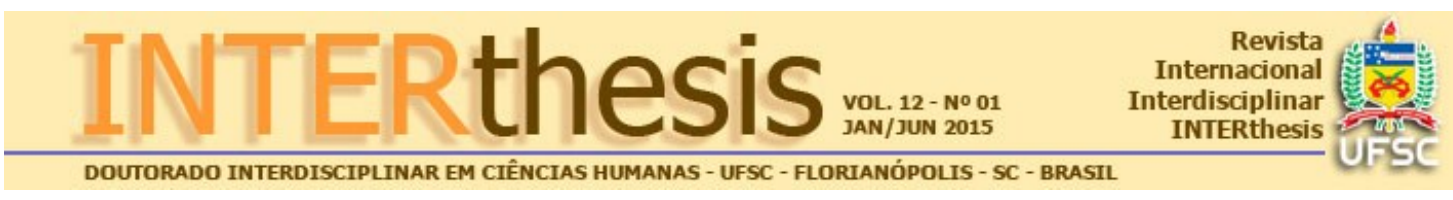

\title{
ANIMAIS, DIVÓRCIO E CONSEQUÊNCIAS JURÍDICAS
}

Camilo Henrique Silva ${ }^{1}$

\section{Resumo:}

O presente trabalho, por meio da pesquisa bibliográfica às leis, às decisões judiciais e à doutrina, tem por escopo trazer ao leitor, de maneira objetiva, as reflexões e o posicionamento do ordenamento jurídico brasileiro sobre o tema dos animais de estimação envolvidos em disputas de guarda no processo de divórcio. Nesse contexto, o escrito aborda a lei brasileira sobre guarda, direito de visita e alimentos, e sua utilização, por analogia, aos casos envolvendo animais de estimação, em razão da falta de norma específica. O texto retrata a tarefa dos magistrados e tribunais de se posicionarem nos casos levados a juízo e apresenta requisitos a serem observados para a decisão da lide, com vistas ao bem-estar e interesse do animal. Na disputa judicial pelos animais de estimação é legal a concessão da guarda e direito de visita aos cônjuges-tutores e a imposição de prestar alimentos ao animal.

Palavras-chave: Direito animal. Bioética. Meio ambiente.

\section{INTRODUÇÃO}

Diante dos avanços da ciência, a cada nova pesquisa se descobre particularidades encantadoras em cada espécie animal. Igualados às máquinas por René Descartes no século XVII, atualmente não se duvida da senciência dos animais não humanos, restando claro à humanidade sua sensibilidade e consciência do mundo.

Desde a antiguidade, os seres humanos encontram-se envolvidos em sua caminhada diária com diversas espécies animais. Quanto aos animais de estimação, indiscutivelmente são parte da maioria dos lares brasileiros. Segundo dados da Associação Brasileira da Indústria de Produtos para Animais de Estimação (Abinpet), em 2012, no Brasil, havia cerca de 106,2 milhões de animais de estimação. Diante desse número expressivo, o país tem a quarta maior população mundial (POPULAÇÃO, 2014).

\footnotetext{
${ }^{1}$ Mestre em Direito Processual e Cidadania pela Universidade Paranaense. Professor Assistente do Curso de Direito na Universidade Federal de Mato Grosso do Sul, Pantanal, MG, Brasil. E-mail: camilo.henrique@ufms.br
} 
Por fazerem parte da vida familiar dos seres humanos, quando ocorre o divórcio, os animais de estimação são envolvidos em disputas judiciais, com os cônjuges pleiteando sua guarda. Diante desse problema, o presente trabalho tem por objeto analisar qual o posicionamento do ordenamento jurídico brasileiro sobre o tema. Dessa forma, com base na doutrina, legislação e julgados recentes, o texto analisa a situação jurídica dos animais de estimação e as consequências legais das disputas de guarda levadas ao Poder Judiciário pelos cônjuges-tutores, diante da não resolução amigável.

Este trabalho tem por escopo analisar a situação dos animais de estimação nas disputas por sua guarda pelos cônjuges-tutores em processo de divórcio. Tais celeumas não ficam adstritas apenas à guarda do animal, tendo desdobramentos no direito de visita e pensão alimentícia, sendo, respectivamente, direito e dever do cônjuge sem a guarda.

O tema é intrigante e merece ampla discussão jurídica, tendo em vista a necessidade de adotar critérios factíveis para a melhor solução dos casos apresentados ao Poder Judiciário. Os critérios para a solução dos conflitos devem ser definidos a partir do bem-estar do animal de estimação, levando em consideração seus interesses, quebrando, portanto, os paradigmas antropocêntricos e especistas formadores da sociedade.

\section{ANIMAIS, DIVÓRCIO E A LEI BRASILEIRA}

O Direito brasileiro, seguindo a definição clássica adotada no mundo jurídico, enxerga os animais não humanos como coisas, bens móveis, semoventes. Nos dizeres do artigo 82, do Código Civil, são "móveis os bens suscetíveis de movimento próprio, ou de remoção por força alheia, sem alteração da substância ou da destinação econômico-social" (BRASIL, 2014a). A fim de reafirmar a situação jurídica de objetos de direito, as crias dos animais, na linguagem da Lei Civil brasileira, pertencem ao seu proprietário, podendo ser vendidos ou doados, conforme estabelece o artigo 1.232 (BRASIL, 2014a).

Para saber quem é o proprietário de um animal de estimação ou doméstico, como cães, gatos e cavalos, basta analisar o documento de pedigree ou, caso o animal não o tenha, sua carteira de vacinação (GAETA, 2003, p. 74). Portanto, o 
animal de estimação é propriedade privada, cabendo ao seu dono, literalmente, decidir o seu futuro.

Todavia, o direito de propriedade não é absoluto. A ordem constitucional brasileira "em seu art. 225, VIII, reconhece que os animais são dotados de sensibilidade, [...] proibindo expressamente as práticas que coloquem em risco sua função ecológica, provoquem a sua extinção ou os submetam à crueldade" (GORDILHO, 2008, p. 138). Diante do mandamento constitucional, apesar de os animais continuarem com seu status de objeto, são vedadas práticas de crueldade. Passa-se a reconhecer a esses seres vulneráveis o direito fundamental à vida, à integridade física e à liberdade, ecoando novas diretrizes às leis infraconstitucionais e à sociedade.

Noutro ponto do Direito Civil estão as normas sobre a formação do casamento e sua dissolução. A partir do casamento estabelece-se entre as partes a sociedade conjugal e o vínculo matrimonial. Rompido o afeto e inexistindo interesse na continuidade do matrimônio, a lei brasileira possibilita o desfazimento dessa união por meio do divórcio, de forma direta. O divórcio direto, sem a exigência do requisito temporal e da prévia separação, foi integrado no ordenamento jurídico pela Emenda Constitucional n. 66, de 14 de julho de 2010, a dar nova redação ao $\S 6^{\circ}$ do art. 226 da Constituição Federal (GONÇALVES, 2012, p. 201-202).

Desfeito o casamento, caso haja questões a serem resolvidas, como bens a partilhar ou futuro da prole, as partes devem entrar em consenso. Impossível o acordo, a decisão sobre as pendências caberá ao magistrado, julgando, conforme a lei e as circunstâncias fáticas, os impasses apresentados.

Considerando os pressupostos acima, grande celeuma tem envolvido o ordenamento jurídico brasileiro no momento do divórcio, quando há na dissolução conjugal disputa pelos animais de estimação. Aparentemente de fácil resolução pelo olhar positivista, pois se o animal é um bem, seu destino deve seguir a do seu proprietário. Logo, em caso de divórcio, o legítimo proprietário ficará com o animal. Essa é a regra, porém, nem sempre a melhor via.

Apesar da clareza legal, o mundo científico e biológico, no mesmo sentido da Constituição Federal brasileira, atesta que os animais não humanos não são meros objetos, como aponta a letra fria do Código Civil. Atualmente, fato notório e indiscutível no mundo, os animais, em especial mamíferos e aves, são considerados 
seres sencientes, dotados de certa consciência, sentem dor, prazer, frio, medo, demonstram sentimentos, fazem escolhas, enfim, se preocupam com o que lhes acontece, dentro, claro, de suas especificidades e particularidades.

Diante desse novo quadro, as normas em vigor não apresentam solução adequada aos casos apresentados ao Poder Judiciário. Cabe ao magistrado, diante de suas convicções (especistas, antropocêntricas ou biocêntricas), dos argumentos lançados nos autos e do fundamento legal e filosófico apresentado, julgar as ações. Muitas vezes as decisões não levam em conta o interesse do animal, mas apenas e tão somente o título de propriedade, na manutenção da visão arcaica do Direito.

Por não haver legislação específica sobre o tema, a fim de resolver a lacuna legislativa, o deputado federal Márcio França (PSB-SP) apresentou na Câmara dos Deputados o Projeto de Lei $n^{\circ} 7196 / 10$, no intuito de regulamentar a guarda de animais de estimação em caso de divórcio sem acordo entre as partes. Atualmente, segundo informações no sítio eletrônico da Câmara dos Deputados, o Projeto de Lei encontra-se arquivado na Mesa Diretora (BRASIL, 2014b).

Segundo o Projeto de Lei $n^{\circ} 7196 / 10$, em seu artigo $2^{\circ}$, caso não haja acordo entre as partes sobre a guarda do animal doméstico, caberá ao juiz determinar com quem ficará o animal, levando em consideração o verdadeiro proprietário ou quem demonstrar capacidade para a posse responsável (BRASIL, 2014b). O projeto mantém o animal como coisa, objeto de direito, não contribuindo, portanto, para uma verdadeira conscientização do ser humano em relação à vida e dignidade desses seres. Todavia, destaca a possibilidade de o animal ficar com quem demonstrar ser o melhor guardião, rompendo com a tradição do domínio.

O projeto de lei traz requisitos objetivos para o juiz determinar com quem ficará o animal de estimação em caso de disputa. Em seu artigo $5^{\circ}$, dispõe quais as condições a serem observadas: a) ambiente adequado para a morada do animal; b) disponibilidade de tempo, condições de trato, de zelo e de sustento; c) o grau de afinidade e afetividade com o animal; d) demais condições que o juiz considerar imprescindíveis para a manutenção da sobrevivência do animal, de acordo com suas características (BRASIL, 2014b).

O Projeto de Lei $n^{\circ} 7196 / 10$ traz ainda a possibilidade da guarda unilateral ou compartilhada, a depender das circunstâncias do caso (art. $4^{\circ}$ ). Na hipótese de guarda unilateral, é previsto o direito de visita da parte não guardiã. Medida 
interessante é a contida no art. $6^{\circ}, \S 4^{\circ}$, ao prever a concessão da guarda do animal a terceiros, se o juiz verificar ser a melhor solução, em razão dos detentores não reunirem condições adequadas (BRASIL, 2014b).

Uma medida não abordada no projeto de lei é a questão dos alimentos ou da pensão alimentícia aos animais. Indiscutível que a manutenção de animais de estimação traz despesas, as quais devem ser suportadas por ambos os detentores, independe de quem ficará com a guarda, seja ela unilateral ou compartilhada.

Apesar do Projeto de Lei $n^{\circ} 7196 / 10$ estar arquivado na Mesa Diretora da Câmara dos Deputados, atualmente está em tramitação o Projeto de Lei no 1058 de 2011, proposto pelo Deputado Federal Dr. Ubiali (PSB/SP), a tratar do mesmo tema (BRASIL, 2014c). O Projeto de Lei n 1058/11 é cópia autêntica do projeto de lei anterior, não merecendo maiores comentários.

O Projeto de Lei n. 1058/2011 sofreu alterações por meio do substitutivo do deputado federal Ricardo Trípoli (PSDB/SP). As mudanças se deram no sentido de incidir as regras legais à união estável de heterossexuais ou homossexuais, e excluir a definição da guarda do animal pela prova da propriedade, mas apenas para o postulante que demonstrar o maior vínculo afetivo com o animal de estimação e melhor aptidão para a posse. Não foi incluída regra sobre pensão alimentícia ao animal. Atualmente, o projeto encontra-se na Comissão de Constituição e Justiça e de Cidadania aguardando deliberação (BRASIL, 2014c).

Enquanto o Projeto de Lei n. 1058/2011 não é aprovado, cabe ao Poder Judiciário estabelecer parâmetros legais sobre a matéria, resolvendo os casos que Ihe são apresentados. O magistrado não pode furtar-se a julgar o caso sob o fundamento de inexistência de previsão legal, pois se utilizará de outros meios, como a analogia, os costumes e os princípios gerais de direito.

\section{OS ANIMAIS NO DIVÓRCIO: COM QUEM FICA O PET?}

Em face da inexistência de lei a regulamentar a guarda dos animais de estimação em caso de divórcio, a tarefa não é das mais fáceis, especialmente quando não há consenso entre as partes. Diante da celeuma, o magistrado deve buscar a melhor solução para cada caso concreto, socorrendo-se à analogia, aos costumes e aos princípios gerais de direito.

R. Inter. Interdisc. INTERthesis, Florianópolis, v.12, n.1, p.102-116, Jan-Jun. 2015 
A melhor solução repousa na preservação dos interesses dos animais de estimação. A simples demonstração da propriedade do animal não é suficiente para a concessão de sua guarda, pois, muitas vezes, a relação afetiva estabelecida entre o não proprietário e o animal é mais forte e saudável. Os envolvidos, portanto, devem demonstrar quem possui melhores condições para a criação do animal. Condições estas que vão desde os fatores psicológicos, sentimentais, financeiros, tempo disponível, entre outros.

A par da inexistência de normas legais, o magistrado deve socorrer-se à analogia para a melhor solução da demanda. Importante observar as regras relativas à guarda estabelecidas no Código Civil e no Estatuto da Criança e do Adolescente. Nesse sentido, ao falar em guarda do animal, por ser este o sujeito vulnerável da relação em disputa, o escolhido como titular terá as mesmas imposições do art. 33 do Estatuto da Criança e do Adolescente, ou seja, prestar ao animal toda a assistência necessária.

Conforme as normas do Código Civil e o pensamento de Gonçalves (2012, p. 292), em regra, a guarda dos filhos trata-se de direito natural dos genitores. No caso dos animais de estimação, a guarda é direito natural dos tutores. Em caso de disputa judicial, a guarda deve ser atribuída a uma das partes, independente do título de propriedade. Mas, se durante a instrução processual ficar evidente tal impossibilidade, a guarda pode ser atribuída a uma pessoa idônea da família de um dos cônjuges, na forma do artigo 1.584, $\S 5^{\circ}$, do Código Civil.

A guarda a ser estabelecida pode ser a unilateral ou a compartilhada, na forma do artigo 1.583 do Código Civil. Pela norma, entende-se por guarda unilateral a atribuída a um dos genitores e "por guarda compartilhada a responsabilização conjunta e o exercício de direitos e deveres do pai e da mãe que não vivam sob o mesmo teto, concernentes ao poder familiar dos filhos comuns" (BRASIL, 2014a).

Ante o imperativo legal, cabe ao magistrado avaliar a melhor solução. A guarda unilateral ou compartilhada pode ser adotada nos casos envolvendo animais de estimação. Para tanto, deve-se observar o melhor para o animal. Segundo Gonçalves (2012, p. 293), a guarda unilateral traz o "inconveniente de privar o menor [animal] da convivência diária e contínua de um dos genitores [tutores]". Por outro lado, na guarda compartilhada, o animal convive com ambos os tutores, não alterando sua rotina. Nessa modalidade, o "compartilhamento visa garantir ao filho 
[animal] que seus genitores [tutores] se empenharão na tarefa de sua criação, minimizando os efeitos danosos que o rompimento da relação entre o casal" (MADALENO; MADALENO, 2013).

Em razão da falta de legislação específica e no intuito de antecipar a solução para o caso de divórcio futuro, casais têm elaborado acordo pré-nupcial, incluindo as questões relativas à guarda, direito de visitas e outros interesses relativos aos animais de estimação. Como exemplo, Kalil e Mendonça (2014) citam o casal Eduardo Henriques e Daniela Piccolo, que em um acordo pré-nupcial selaram o destino de seus doze cães da raça cocker. Neste documento, o casal decidiu com quem ficaria cada animal, o direito de visita quinzenal e a necessidade de permissão do outro para eventuais cruzas.

Outro exemplo de acordo extrajudicial ocorreu com Elizabeth Maximo e seu ex-marido. Para solucionar a questão, o ex-marido ficou com Marcela, uma fêmea de hamster. Elizabeth continuou com Maristela e Francis, duas cachorras. O exmarido firmou compromisso de pagar pensão alimentícia às cachorras, para auxiliar nas despesas com alimentação, em contrapartida, fixou-se o direito de visitá-las. Atualmente, o ex-marido não mantém a rotina de visitas, mas arca com metade das despesas veterinárias (FERNANDES, 2014).

Quando não há acordo entre os tutores a disputa é levada ao Poder Judiciário, cabendo ao magistrado avaliar o pedido. No ano 2000, por exemplo, em uma celeuma por animais de estimação na cidade de Brasília, a justiça teve de se pronunciar sobre a guarda de dois poodles. No processo, a perita Claudia Pizzolato elaborou parecer favorável ao ex-marido Antonio Bahia, que tinha ganhado os cães de sua esposa, porém, nos documentos dos animais constava a propriedade da exmulher. Apesar de o parecer da perita ser favorável ao ex-marido, pois cuidava dos cães a mais de dez anos e o afastamento seria prejudicial aos animais, o magistrado desconsiderou o estudo e decidiu pela guarda à ex-mulher, proprietária legal dos cachorros (FERNANDES, 2014).

Diversamente do fato julgado em Brasília, Eithne e Akers (2011, p. 218) apresentam dois casos norte-americanos, onde o magistrado desconsiderou a regra da propriedade, levando em consideração o melhor para os animais de estimação. No primeiro caso, em uma decisão em lowa, apesar de o animal ter sido presente para a mulher no natal, o tribunal decidiu que o cão deveria ficar com o marido. No 
segundo, o tribunal, na contenda de Rogers contra Rogers, desconsiderou a posse do animal antes do casamento, ao julgar a guarda e o direito de visita.

Recente caso de pedido de guarda compartilhada ocorreu na Espanha. O casal era separado a mais de cinco anos e a guarda do animal estava com o exmarido. A ex-mulher, Paqui Barrios, fez o pedido judicial para compartilhar a guarda do cão. O magistrado Luiz Romualdo Hernández, titular do Juizado de Primeira Instância número 2 de Badajoz, acatou a solicitação postulada, deferindo a guarda compartilhada. Laude, o cão, passou a ficar em períodos sucessivos de seis meses com cada tutor (REUTERS, 2014).

Para os casos sem acordo entre os tutores, a melhor solução é a que visa o bem-estar e interesse do animal, descartando o critério da propriedade como fundamento. Nesse sentido, Eithne e Akers (2011, p. 218-219) apontam para requisitos específicos a serem utilizados na solução do litígio. Portanto, deve-se levar em conta como é a vida do animal, suas saídas para caminhadas, se no novo lar haverá conflitos de relacionamento com crianças, adultos ou outros animais, qual dos tutores é mais afetuoso, entre outras situações.

A fim de uma melhor solução para os casos em disputa, Eithne e Akers (2011, p. 226) sugerem a figura de um representante para o animal, a ser nomeado nos autos pelo magistrado. Esse interventor pode ser um membro de entidade de proteção animal ou alguém com conhecimentos específicos sobre o tema. Sua função seria a de defender os interesses do animal e subsidiar o juiz com informações significativas para a melhor decisão da causa.

Nos casos de divórcio, onde os tutores não consigam chegar a um consenso sobre a guarda dos animais de estimação, o Poder Judiciário, ao analisar os casos, deve fazer prevalecer o melhor interesse dos animais, ponderando cuidadosamente todos os aspectos fáticos. Para tanto, tem como fundamento as regras do Estatuto da Criança e do Adolescente e do Código Civil, cabendo sua utilização por analogia.

Desse modo, por serem os animais seres sencientes, a simples definição da guarda pelo título de propriedade não se coaduna com o melhor entendimento e solução, pelo contrário, demonstra o apego dos operadores do Direito a preconceitos especistas e o descompasso com a realidade científica e social. 


\section{ANIMAIS E O DIREITO DE VISITA}

No ordenamento jurídico brasileiro o direito de visita está estabelecido e garantido pelo Código Civil, em seu artigo 1.589, ao dispor que o "pai ou a mãe, em cuja guarda não estejam os filhos, poderá visitá-los e tê-los em sua companhia, segundo o que acordar com o outro cônjuge, ou for fixado pelo juiz" (BRASIL, 2014a). Em razão de não haver norma específica para o caso dos animais de estimação, a regra do artigo 1.589 da Lei Civil pode ser utilizada por analogia, a fim de resolver as disputas apresentadas ao Poder Judiciário.

O direito de visitas trata-se de um dever dos genitores e um direito dos filhos. Nesse aspecto, para Madaleno e Madaleno (2013), tal garantia legal pode ser atribuída mesmo se "o genitor não guardião for viciado em tóxicos, alcoólatra inveterado ou psicopata, porém restringido a um local adequado, determinado em juízo e com o acompanhamento de terceira pessoa, a visitação assistida".

Em não havendo acordo entre os tutores do animal de estimação sobre a visitação, o magistrado, por analogia, deve utilizar-se das regras do direito de visita estabelecidas no Código Civil. A convivência com os tutores é direito do animal. Portanto, em uma disputa judicial, ao cônjuge sem a guarda, diante da convivência e sentimento nutrido, e para o próprio bem do animal, resta solicitar ao juiz a concessão do direito de "visita, e até mesmo à participação na escolha da árvore genealógica do animal com pedigree" (GAETA, 2003, p. 74).

Os cônjuges podem estabelecer o direito de visita amigavelmente, por meio de acordo, desde que o interesse e o bem-estar do animal de estimação sejam preservados. Não havendo consenso entre as partes, caberá ao magistrado a árdua tarefa de decidir o caso. Para tanto, deve utilizar-se, analogamente, do instituto civil do direito de visita para a solução, tendo em vista o melhor para o animal, a fim de não privá-lo da convivência dos tutores, se lhe for salutar.

\section{ANIMAIS E O DIREITO A ALIMENTOS}

No âmbito do Direito, numa acepção técnica, a expressão alimentos compreende "não só o indispensável ao sustento, com também o necessário à manutenção da condição social e moral do alimentando" (GONÇALVES, 2012, p. 
498). Os alimentos estão além da alimentação diária, abarca todo o complexo de bens necessários à vida, como habitação, saúde, educação, lazer, entre outros.

Para Gonçalves (2012, p. 499), o "dever de prestar alimentos funda-se na solidariedade humana e econômica que deve existir entre os membros da família ou os parentes". O Estado passa a normatizar tal relação, a fim de impor à família a obrigação legal de prestar alimentos aos seus pares. Se tal fato não for observado caberá tal providência ao próprio Estado, responsável pelo amparo dos carentes e desprotegidos.

No direito brasileiro, as normas de prestação de alimentos encontram-se dispostas no Código Civil, nos artigos 1.694 e 1.695. Estabelece o artigo 1.694 que "os parentes, os cônjuges ou companheiros [podem] pedir uns aos outros os alimentos de que necessitem para viver de modo compatível com a sua condição social, inclusive para atender às necessidades de sua educação" (BRASIL, 2014a). Ao artigo 1.695 são "devidos os alimentos quando quem os pretende não tem bens suficientes, nem pode prover, pelo seu trabalho, à própria mantença, e aquele, de quem se reclamam, pode fornecê-los, sem desfalque do necessário ao seu sustento" (BRASIL, 2014a).

Analisando as normas sobre alimentos, as mesmas podem ser utilizadas por analogia na relação existente entre os tutores e seus animais de estimação. Apesar de se estar diante de uma responsabilidade familiar, embasada no parentesco sanguíneo, a relação entre os tutores e seus animais é de afinidade, cabendo, desse modo, uma responsabilidade civil obrigacional.

Não restam dúvidas das responsabilidades de um tutor para com seus animais de estimação. Como nas civis entre familiares, tais responsabilidades vão além da alimentação, englobando as necessidades do animal com saúde, lazer, moradia, entre outras. A obrigação de prestar alimentos configura-se um dever indeclinável dos tutores para com seus animais, independentemente se estão ou não em sua guarda.

Em caso de divórcio, o animal de estimação tem o direito de receber pensão alimentícia do tutor que não lhe detém a guarda, por tratar de obrigação indeclinável, um direito fundamental e essencial à manutenção de sua vida com dignidade. Se os tutores não acordam, é perfeitamente possível o ajuizamento de ação específica para a solução do impasse. Ao Poder Judiciário cabe impor o dever de alimentar ao 
tutor não guardião, estipulando o valor da pensão alimentícia de acordo com as necessidades do animal-alimentando e a possibilidade de pagamento do tutoralimentante.

No Brasil, os pedidos judiciais de pensão alimentícia não são muito comuns, com as disputas restritas à guarda do animal. Entretanto, hipótese interessante ocorreu em São Paulo, quando a ex-mulher, que havia ficado com a guarda de dois cachorros após a separação, pediu pensão ao ex-marido para os animais. A $1^{\text {a }}$ Câmara de Direito Privado do Tribunal de Justiça de São Paulo acatou o pedido feito de $R \$ 250,00$ de pensão para cada cão. Decidiu o Poder Judiciário pelo direito de os animais receberem, cada um, $R \$ 250,00$ mensais a título de pensão alimentícia vitalícia (BARBOSA, 2014).

Perfeitamente possível e factível a disposição de deveres aos cônjuges, no divórcio, para os animais de estimação. Se a responsabilidade em cuidar do animal de estimação é dos tutores, consequentemente, as despesas com alimentação, vacinas, médico veterinário, e outras tantas, devem ser suportadas e compartilhadas de maneira proporcional aos ganhos de cada um, levando-se em conta as necessidades do animal. Ao cônjuge-tutor que não estiver com a guarda do animal de estimação é legal a estipulação de pensão alimentícia, no escopo de fazer frente a tais despesas.

\section{CONSIDERAÇÕES FINAIS}

No Brasil, como em outros países, não existe diploma legal a tratar da guarda, do direito de visita e da pensão alimentícia aos animais de estimação após o divórcio do casal. Apesar da lacuna legislativa, os tribunais têm enfrentado essas questões diariamente. Não obstante a tendência conservadora de privilegiar a propriedade do animal para a solução das demandas, aos poucos os magistrados tem pautado as decisões pelo bem-estar e interesse do animal de estimação.

Ao deixar de julgar pela propriedade, privilegiando o melhor interesse do animal, aos poucos se altera a percepção dos animais não humanos no meio jurídico brasileiro. Antes mera propriedade, bem móvel, semovente, o animal passa a ser considerado como um indivíduo, com valores em si mesmo, sujeito de uma vida, de interesses, e desse modo, com direito à proteção real pelo ordenamento 
pátrio. Nesse norte, Gordilho (2008, p. 122) entende que "o status jurídico dos animais [no direito brasileiro] já se encontra a meio caminho entre a propriedade e a personalidade jurídica".

Claramente urge a necessidade de uma legislação a regulamentar a situação dos animais não humanos em caso de divórcio, mas não para reafirmar seus status de objeto, mas sim, para enxergá-los como sujeito de direito. Não se aguarda a lei para determinar a guarda do animal ao proprietário, mas para deferi-la àquele com condições de conceder-Ihe uma vida digna, saudável, sem qualquer tipo de sofrimento, maus-tratos.

Nas questões de divórcio envolvendo a guarda de animais de estimação espera-se dos tribunais uma solução em benefício dos animais e não de seus tutores. O magistrado, ao se deparar com tal situação, deve promover um verdadeiro debate para chegar ao melhor resultado para o animal de estimação, independente da vontade dos postulantes à tutela, pois somente assim, o direito desses seres vulneráveis será respeitado e garantido.

Portanto, não restam dúvidas da possibilidade jurídica de ações relativas à guarda, direito de visita e pensão alimentícia em decorrência do embate sobre a tutela dos animais de estimação no caso de divórcio do casal. Quando não houver acordo entre os cônjuges-tutores sobre tais temas, o Poder Judiciário não pode abster-se de decidir o caso, mas deve levar em consideração o interesse e bemestar do animal, e não a mera vontade das partes ou o título de propriedade. 


\title{
ANIMALS, DIVORCE AND LEGAL CONSEQUENCES
}

\begin{abstract}
This work, through bibliographic research of laws, judicial decisions and doctrine, intends to present to the reader, in an objective manner, the reflections and the position of the Brazilian legislation on the issue of domestic animals involved in disputes custody in divorce proceedings. In this context, this paper addresses the Brazilian legislation regarding custody, visitation rights and alimentation, and its use, by analogy, in the case of pets, due to the absence of a specific rule. We describe how the judges and courts are positioned in the cases prosecuted and present the requirements to be followed to decide the dispute, with a view to the welfare and interest of the animal. In proceedings involving pets, it becomes legal to give the custody and visitation rights to spouses/guardians and establish an obligation to provide food to animals.
\end{abstract}

Keywords: Animal law. Bioethics. Environment.

\section{ANIMALES, DIVORCIO Y CONSECUENCIAS LEGALES}

\section{Resumen}

Este trabajo, a través de la investigación bibliográfica de las leyes, las decisiones judiciales y la doctrina, propone presentar al lector, de una manera objetiva, las reflexiones y la posición de la legislación brasileña sobre el tema de los animales domésticos involucrados en disputas de custodia en el proceso de divorcio. En este contexto, este trabajo aborda la legislación brasileña en lo que concierne a la custodia, los derechos de visita y de alimentación, y su utilización, por analogía, en los casos de animales domésticos, debido a la ausencia de una norma específica. Describimos la manera en que los magistrados y los tribunales se posicionan en los casos enjuiciados y presentamos los requisitos que han de seguirse para decidir la controversia, con miras al bienestar y al interés del animal. En los litigios por los animales domésticos, resulta legal otorgar la custodia y los derechos de visita a los cónyuges/tutores y establecer la obligación de proporcionar alimentos a los animales.

Palabras clave: Derecho animal. Bioética. Medio ambiente. 


\section{REFERÊNCIAS}

BARBOSA, R. Separação faz casais irem à Justiça por guarda e pensão de animais de estimação. UOL, São Paulo, 05 julho 2013. Disponível em: http://noticias.uol.com.br/cotidiano/ultimas-noticias/2013/07/05/separacao-fazcasais-irem-a-justica-por-guarda-e-pensao-de-animais-de-estimacao.htm Acesso em: 15 jan. 2014.

BRASIL. Lei n 10.406, de 10 de janeiro de 2002. Institui o Código Civil. Diário Oficial [da] República Federativa do Brasil, Brasília, DF, 10 janeiro 2002. Disponível em: http://www.planalto.gov.br/ccivil 03/leis/2002/l10406.htm . Acesso em: 20 out. 2014.

. Congresso Nacional. Câmara dos Deputados. Projeto de Lei n 7196 de 2010. Dispõe sobre a guarda dos animais de estimação nos casos de dissolução litigiosa da sociedade e do vínculo conjugal entre seus possuidores, e dá outras providências. Disponível em: http://www.camara.gov.br/sileg/integras/765006.pdf. Acesso em: 30 mai. 2015.

Congresso Nacional. Câmara dos Deputados. Projeto de Lei n 1058 de 2011. Dispõe sobre a guarda dos animais de estimação nos casos de dissolução litigiosa da sociedade e do vínculo conjugal entre seus possuidores, e dá outras providências. Disponível em:

http://www.camara.gov.br/proposicoesWeb/fichadetramitacao?idProposicao=498437. Acesso em: 22 out. 2014.

EITHNE, M.; AKERS, K. "Quem fica com os gatos... Você ou eu?" Análise sobre a guarda e o direito de visita. Questões relativas aos animais de estimação após o divórcio ou a separação. Revista Brasileira de Direito Animal. Ano 6, n. 9, jul./dez, p. 207-238. Salvador: Evolução, 2011.

FERNANDES, N. Quando os donos se separam. Época, São Paulo, 23 outubro 2010. Disponível em:

http://revistaepoca.globo.com/Revista/Epoca/0,EMl181588-15228,00QUANDO+OS+DONOS+SE+SEPARAM.html. Acesso em: 23 out. 2014.

GAETA, A. Código de Direito Animal. São Paulo: WVC, 2003.

GONÇALVES, C. R. Direito civil brasileiro: direito de família. 9. ed. São Paulo: Saraiva, 2012. 
GORDILHO, H. J. S. Abolicionismo animal. Salvador: Evolução, 2008.

KALIL, M.; MENDONÇA, M. Nem Freud explica. Época, São Paulo, 13 dezembro 2010. Disponível em:

http://revistaepoca.globo.com/Revista/Epoca/0,EMl160406-15228,00-

NEM+FREUD+EXPLICA.html. Acesso em: 30 mai. 2015.

MADALENO, A. C. C.; MADALENO, R. Síndrome da Alienação Parental: a importância de sua detecção com seus aspectos legais e processuais. Rio de Janeiro: Forense, 2013.

POPULAÇÃO de pets cresce $5 \%$ ao ano e brasil é quarto no ranking mundial. Cães \& Gatos VET FOOD, Sorocaba, 5 novembro 2013. Disponível em: http://www.caesegatos.com.br/populacao-de-pets-cresce-5-ao-ano-e-brasil-equarto-no-ranking-mundial/. Acesso em: 20 out. 2014.

REUTERS. Juiz espanhol concede a casal guarda compartilhada de cachorro. Folha.com, São Paulo, 14 outubro 2010. Disponível em:

http://www1.folha.uol.com.br/mundo/814792-juiz-espanhol-concede-a-casalguarda-compartilhada-de-cachorro.shtml. Acesso em: 25 out. 2014.

Artigo:

Submetido em 21.05.2015

Aceito em 01.06.2015 